\title{
La dimensión territorial del espacio religioso chilote: fusión ejemplar del patrimonio tangible con el intangible ${ }^{1}$
}

\author{
Antonio Sahady Villanueva², Felipe Gallardo Gastelo ${ }^{2}$ \\ y José Bravo Sánchez ${ }^{2}$
}

\begin{abstract}
RESUMEN
El poder del patrimonio tangible se identifica durante la celebración de las fiestas religiosas de Chiloé, con las iglesias que ofician de sedes. De manera simultánea, en ese mismo acto, el patrimonio intangible se expresa en los ritos ceremoniales, en las costumbres y en la cultura de la vida y de la muerte. Cuatro casos, de distinta escala geográfica, han permitido demostrar que el fervor religioso es cualificado por una serie de condicionantes de orden físico y social. El análisis territorial ofrece, finalmente, sugerentes conclusiones, conforme sea la categoría de cada una de las cuatro entidades pobladas que se seleccionaron de acuerdo al Instituto Nacional de Estadísticas de Chile (INE).
\end{abstract}

Palabras clave: Geografía cultural, arquitectura patrimonial, patrimonio territorial, fiesta religiosa, modelo del espacio religioso de Chiloé.

\begin{abstract}
The power of tangible patrimony is identified, during the celebration of religious events of Chiloé, with churches that act as headquarters. Simultaneously the intangible patrimony is expressed in the ceremonial rites, in the customs and the culture of life and death. Four cases, of different geographic scale, have allowed to demonstrate that the religious fervor is qualified by a series of conditions of physical and social order. The territorial analysis, offers, finally, suggestive conclusions, in agreement to the category of each one of the four settlements that were selected, according with the National Institute of Statistics of Chile's (NSI) criteria.
\end{abstract}

Key words: Cultural geography, patrimonial architecture, territorial patrimony, religious celebration, Chiloe's model of religious space.

Cuando las costumbres, las creencias, las aspiraciones y los sueños son compartidos por una sociedad determinada, adquieren dimensiones territoriales (Claval, 1995). Visto de otro modo, el territorio se carga de humanidad cuando convergen en él poderosos atributos intangibles; un territorio que res-

1 Artículo recibido el 11 de enero de 2008 y aceptado el 12 de septiembre de 2008. ponde, en ocasiones, tanto a lógicas funcionales como a lógicas simbólicas. Es sabido que los traslados religiosos por parte de fieles y peregrinos dotan a los lugares sagrados de incuestionables potencialidades turísticas.

\footnotetext{
2 Instituto de Restauración Arquitectónica. Universidad de Chile (Chile).E-mail: asahady@uchile.cl; felipe.gallardogastelo@gmail.com; marcelobravo2000@yahoo.com
} 
El geógrafo francés Jean Pierre Bertrand (1999) analizó el dominio que ejercían las religiones sobre las relaciones sociales; estudió, además, las diversas formas de organización social respecto del territorio que las cobijan y, desde luego, su conducta en los espacios religiosos. Realizó, desde la geografía, un acercamiento a la peregrinación que las comunidades realizan hasta lugares sacros.

En Italia, por su parte, la Dra. Stefania Mangano (1990) se aproximó al tema a través de su obra Territorio y santuarios: el caso Liguria, en la que destaca a Liguria como una región de alta concentración de movimientos religiosos y actividades turísticas.

Otro autor, Alberto Capacci, en Los santuarios en Italia: encuentro entre religión y turismo, prefiere no profundizar en la relación turismo/religión y se inclina por una serie de consideraciones pragmáticas y específicas, aprobando que sea la propia Iglesia Católica la que promueva el ecumenismo y el turismo religioso (Capacci, 1999).

Por último, el croata Boris Vukonic, en su obra Tourism and religión (1996), hace hincapié en la interdependencia entre los conceptos religión y turismo contemporáneo.

Es evidente que en Latinoamérica la religión se ha pluralizado y que la Iglesia Católica ha perdido su papel casi monopólico. En ese contexto, hubo unos cuantos fenómenos que lo demostraron: las comunidades protestantes alcanzaron un nuevo modelo; las religiones indígenas se revitalizaron; la religiosidad se manifestó en círculos no convencionales. Asimismo, se disolvió el núcleo fuerte del laicismo (Parker, 1994) y del anticlericalismo criollo, que se manifestó en el reconocimiento y respeto por las religiones, inclusive en un país tan laicista como lo es México. Al respecto, son determinantes los tratados de Roberto Blancarte (1992), Rodolfo Casillas (1996) y Cristián Parker Gumucio (1994), que ratifican el trascendental progreso de la exploración sobre la religión y su expresión espacial en el Estado mexicano. A partir de las dos últimas décadas del siglo XX, el modelo de la secularización comenzó a ser discutido. Según Peter Berger (2001), la modernización conduce inevitablemente a una desvalorización de la religiosidad.

Una geógrafa brasileña -Zeny Rosendahal- sintetizó, de manera brillante, en sus obras Espaço \& religião (1996), Paisagem, Tempo e Cultura (1998) y Hieropolis: o sagrado e o urbano (1999), las relaciones espaciales que se dan entre las peregrinaciones y el turismo. Basó su metodología de análisis en el estudio del paisaje y las formas geográficas, en los rituales religiosos y el tipo de función (devocional, política, turística). Consideró, asimismo, romerías e interacciones espaciales, la fuerza de las redes sociales, los desplazamientos del participante $y$ el alcance territorial.

Pero también las fiestas religiosas de Chiloé y su territorialidad han sido objeto de estudios diversos. Casi todos ellos han centrado su atención en las ceremonias. Renato Cárdenas y C. Trujillo (1987), Isidoro Vásquez de Acuña (1956) y Rodolfo Urbina (1990) lo han hecho desde su óptica histórica; y desde la perspectiva arquitectónica son interesantes los trabajos realizados por Ignacio Modiano (1994), Hernán Montecinos (1995) y Lorenzo Berg (1998). En ellos el espacio religioso chilote está protagonizado por el templo; adyacente a él la explanada permite la reunión de la comunidad. A veces, el cementerio se extiende a un costado del templo. Por último, el muelle -excepcionalmente el puerto- cumple su papel: recibir a los fieles externos a la comunidad (Modiano, 1994).

El geógrafo Marcelo Bravo (2004) aventuró un modelo mediante el que pretende demostrar que el espacio religioso chilote obedece a un patrón concéntrico, cuyo ente ordenador y foco es la iglesia $y$, en torno a ella, el anillo que comprende el espacio religioso chilote.

\section{Materiales y métodos}

La confluencia de dos áreas disciplinares -patrimonio arquitectónico y geografía cultural- ofrece la posibilidad de observar un fenómeno desde dos perspectivas simultáneas. Pero es un hecho que el conocimiento ha de construirse paso a paso, con una pro- 
funda compenetración de las situaciones en terreno. Inicialmente surgen en el proceso algunas preguntas que durante la investigación se procura desarrollar. ¿Qué se entiende por espacio religioso?, ¿cómo funciona un espacio religioso?, ¿cómo conservar un espacio religioso?

Las respuestas exigen, al comienzo, una metodología de tipo exploratoria. Lo primero: una intensa revisión bibliográfica acerca del tema de las iglesias y su relación con el entorno cercano; en particular, las iglesias chilotas, estrechamente ligadas al pensamiento mágico de los isleños. Cabe señalar que el estudio entre las iglesias y su relación con la comunidad en Chiloé no ha sido todavía profundizado. Por lo general, este aspecto se toca de forma tangencial. El énfasis se ha puesto más en los aspectos morfológicos que en los espaciales y sociales. Para ello se busca, mediante abundante apoyo bibliográfico, explicar qué se entiende por espacio religioso. Adicionalmente, se estableció, de manera documentada, la importancia de la iglesia como elemento ordenador del espacio chilote. Por último, se intentó la delimitación del rol tanto material como inmaterial de la iglesia para la comunidad chilota.

En el proceso se reunieron los antecedentes bibliográficos, fotográficos y audiovisuales provenientes de fuentes confiables: de la Facultad de Arquitectura y Urbanismo y de la Facultad de Ciencias Sociales y Humanidades, ambas de la Universidad de Chile. Se examinaron, asimismo, el Archivo Fotográfico de la Universidad de Chile y el Archivo de Documentación Chilote.

En una segunda fase, la investigación adoptó un cariz más analítico. En esta etapa se especificaron las propiedades más destacadas del espacio religioso chilote, a través de la medición, descripción y evaluación de las diversas partes del conjunto, a saber: la iglesia, la plaza o explanada y el cementerio, también el muelle, cuando gravita en el conjunto. Se procedió, entonces, a la identificación y localización de casos tipo que ameritasen un análisis.

En la fase última, la metodología se tornó explicativa, de manera que permitiera desvelar las causas que han dado origen a los espacios religiosos chilotes y cómo es que la comunidad ha logrado mantenerlos por más de 500 años; permitió, además, conocer los efectos del modelo de globalización, que pugna desde hace 20 años por romper el cerco de resistencia que impone la tradición chilota.

El tamaño de la muestra fue otorgado por el tipo de entidad poblacional (caserío, aldea, pueblo y ciudad). Pero también por la importancia de la fiesta religiosa y el tamaño de iglesia y su entorno arquitectónico para la comunidad chilota.

Atendiendo a la definición de Harvey (1983), los modelos pueden utilizarse: “...para relacionar la teoría con la experiencia, la experiencia con la imaginación, las teorías con otras teorías, las creaciones con la teoría formal y así sucesivamente..." (Harvey, 1983: 65).

Esta afirmación se cumple en el caso del espacio religioso chilote. Así ha quedado demostrado en la investigación histórica desarrollada por Urbina y Cárdenas. En el campo de la arquitectura, un buen número de estudios académicos -Hernán Montecinos (1995), entre ellos- avalan este asierto.

Según Urbina (1990), los indígenas deben a los jesuitas el utilizar, como centro del espacio, las rústicas y primitivas capillas del archipiélago. La misma situación se mantiene hasta nuestros días. Posteriormente, en la década 1980-1990, Montecinos (1995) y Modiano (1994) desarrollaron esta idea, que más tarde Bravo (2004) ilustró en un esquema concéntrico, a partir de la iglesia como núcleo (Figura $N^{\circ} 1$ ). Dicho modelo tiene relación con los modelos de estructura interna de la ciudad, correspondiente a los de Teoría clásica de la estructura de la ciudad de Burgess y UIman-Harris.

Para los fines de la presente investigación se aplicó el modelo señalado a cuatro casos de estudio, de diferente escala de asentamiento humano. Se puede comprobar, en el proceso, de qué manera el modelo concéntrico evoluciona hacia un modelo multinuclear. 
Figura $\mathrm{N}^{\circ} 1$

Modelo concéntrico del espacio chilote (tiene en el templo su centro de la vida cultural, social y económico)

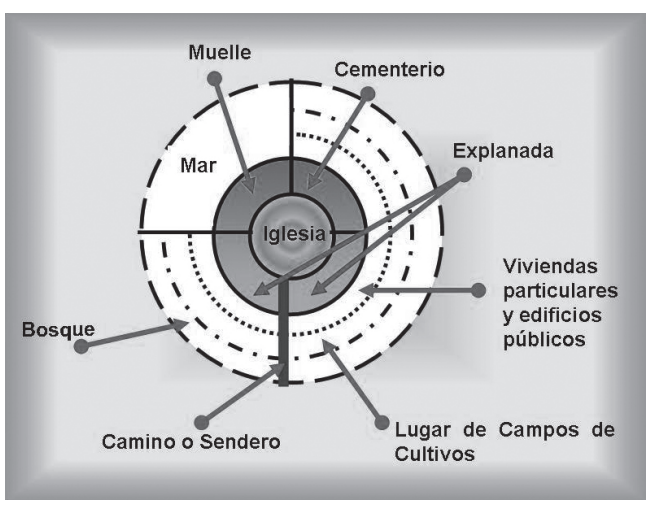

Fuente: Bravo, 2004.

\section{El escenario geográfico}

El universo de estudio se centra en la provincia de Chiloé, cuya superficie total es $9.181,6 \mathrm{~km}^{2}$. Está conformada por dos sectores claramente diferenciados: la isla Grande de Chiloé y el archipiélago integrado por cuarenta islas menores.

Con $8.300 \mathrm{~km}^{2}$, la isla Grande tiende a ser un rectángulo de $250 \mathrm{~km}$ de largo por 50 $\mathrm{km}$ de ancho. El archipiélago, a su vez, localizado entre los paralelos $41^{\circ} 44^{\prime}$ y $43^{\circ}$ $17^{\prime}$ de latitud Sur y entre los meridianos $72^{\circ}$ $45^{\prime}$ y $74^{\circ} 30^{\prime}$ de longitud Oeste, cuenta con una superficie de $881,6 \mathrm{~km}^{2}$ y se subdivide en tres grupos de islas o microarchipiélagos: Quinchao, Chauques (o Butachauques) y Lemuy.

Administrativamente la provincia de Chiloé pertenece a la Región de Los Lagos, siendo sus límites geográficos los siguientes: al norte, el canal de Chacao; al sur, la isla Guafo; al oriente, las islas Desertores y el canal Apiao; y al poniente, el océano Pacífico. En el censo de población de 2002 registró 154.766 habitantes $(14,42 \%$ regional), y un crecimiento intercensal con respecto del censo de 1992 de 1,71\% (el promedio regional es de 1,23\%). Espacialmente la población se distribuye del siguiente modo: el $56 \%$ corresponde a entidades urbanas y el $44 \%$ a áreas rurales. En el último censo, el
INE identificó un total de 3 ciudades, 6 pueblos y 9 aldeas como núcleos de concentración demográfica, siendo los dos primeros de carácter urbano y las aldeas agrupamientos rurales (INE, 2005).

El poblamiento de Chiloé insular es el resultado de una doble situación; por un lado, obedece a un contingente de población autóctona (cuncos) y, por otro, a una política de colonización Ilevada adelante por la autoridad central del país, con miras a hacer efectiva la ocupación del territorio.

La población actual se localiza preferentemente en la vertiente oriental de la isla Grande, es decir, de cara hacia el mar interior de Chiloé. Ello se explica, indudablemente, por condicionantes de orden geográfico, en especial geomorfológicas y climáticas. En el hecho, la cordillera de la Costa, representada aquí por la de Piuché y Pirulil -cuyas alturas no alcanzan magnitudes de gran envergadura- son, sin embargo, lo suficientemente importantes como para impedir la penetración de los vientos permanentes del oeste, cargados de humedad. Esta situación determina un área protegida y con un clima más benigno en la vertiente oriental, por lo que es más favorable para el asentamiento humano. Este mismo hecho influye en la localización de la población de las islas próximas a la isla Grande de Chiloé. Allí se disgrega por toda la superficie de las islas, con solo algunos lugares de concentración que sirven de puntos de contacto entre las islas menores y la isla Grande de Chiloé. Es el caso de Puqueldón, en isla Lemuy; Achao y Curaco de Vélez en la Isla de Quinchao. Por coincidencia, esta zona de la provincia ha tenido una rica vida económica, social, religiosa y patrimonial, expresada en una cultura que sobresale por sí misma en el contexto del territorio nacional.

Finalmente, el área de estudio seleccionada en la provincia de Chiloé comprende a la franja territorial delimitada por las coordenadas geográficas desde los $42^{\circ} 25^{\prime}$ a $42^{\circ} 30^{\prime}$ de latitud Sur y de los $73^{\circ} 15^{\prime}$ a $73^{\circ} 48^{\prime}$ de longitud Oeste. La elección de las localidades pobladas -Caguach, LlauIlao, Achao y Castro- se justifica porque pertenecen a las distintas categorías propuestas por el INE. 
La muestra de ese estudio, siempre dentro del archipiélago chilote, consideró cuatro casos tipo (Figura $N^{\circ} 2$ ), cuyo espacio religioso se analizó según los siguientes criterios: a) Tipo de localidad o entidad poblada, de acuerdo a las determinaciones del INE: ciudad, aldea y caserío rural o villorrio; b) Que cuenten con una fiesta religiosa; y c) Que exista acceso a la información, tanto en gabinete como en terreno. Los casos seleccionados fueron: Castro, como ciudad; Achao, como pueblo; Llaullao, como aldea; y Caguach, como caserío rural.

\section{Génesis histórica del espacio religioso en Chiloé}

A la llegada de los españoles, el archipiélago chilote estaba habitado por los chonos y veliches, población indígena que se distribuía a lo largo de las costas orientales del archipiélago. Vásquez de Acuña (1956) señala que cuando los conquistadores arribaron a Chiloé, tras reconocer el territorio y tomar posesión de él -sin derramamiento de sangre-, lograron adaptarse a la población existente, estableciendo sus caseríos según el patrón indio.

Si bien el arribo de los españoles, en 1567, impuso la presencia religiosa en Chiloé, solo en 1608, a la llegada de los jesuitas, se inició la evangelización de los pueblos chilotes. Expulsados por Decreto Real en 1750 -aunque solo dejaron el archipiélago en 1767-, durante 159 años se encargaron de formar y consolidar una expresión religiosa única, teniendo entre sus actividades la confección de imágenes y cuanta artesanía pudo servir a sus fines misionales.

Cuando los jesuitas recalaron en Chiloé, la población indígena se hallaba dis-

Figura $\mathrm{N}^{\circ} 2$

Área de estudio
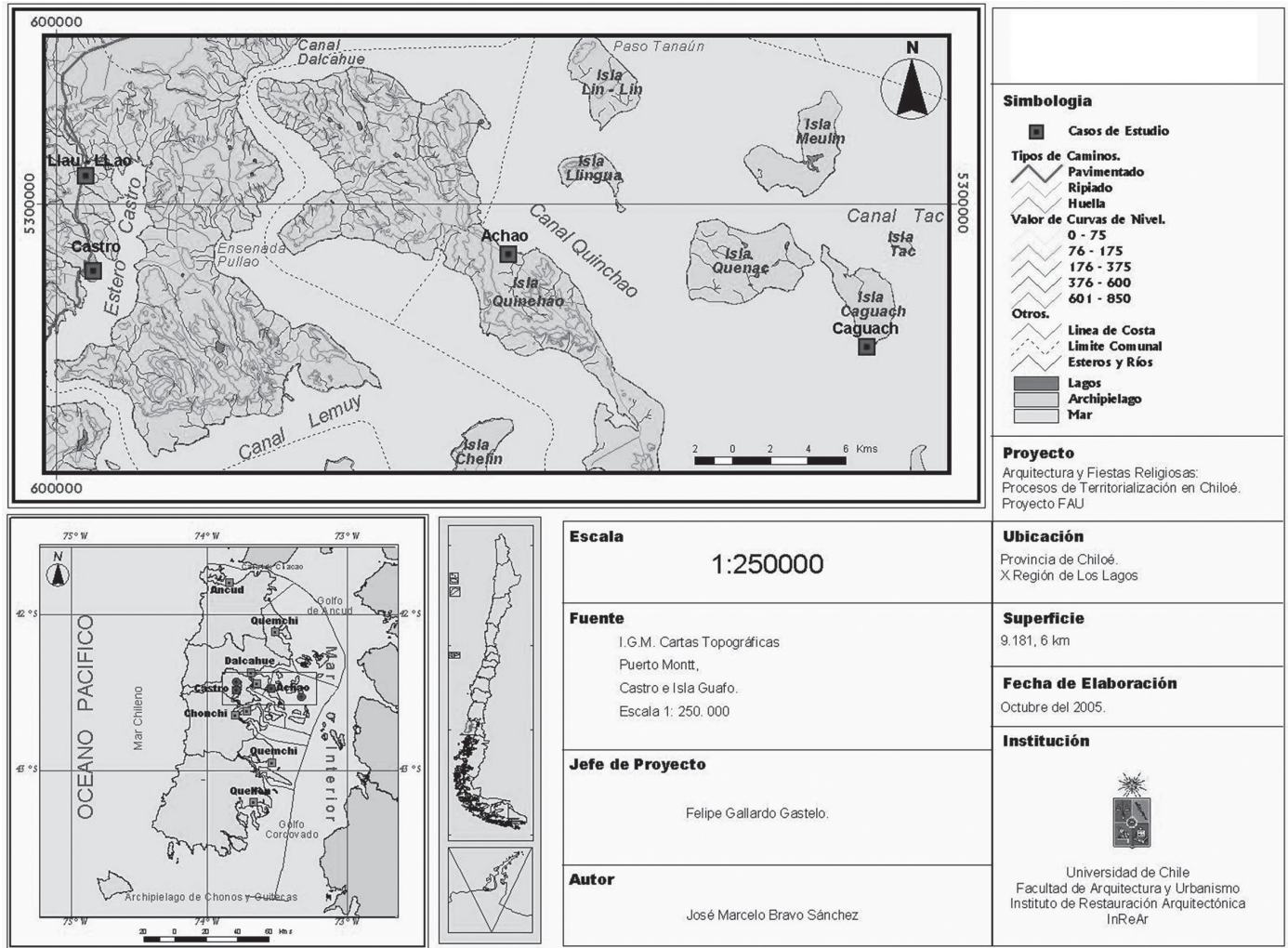

Fuente: INREAR, 2006-2007. 
gregada a lo largo de las costas del archipiélago, pero los reunía el nguillatún, que era su rogativa religiosa; los juegos de palín o linao; un machitún para aliviar a un enfermo o un cahuín para celebrar algún acontecimiento. Ni los veliches ni los chonos disponían de templos o construcciones para sus reuniones rituales o festivas (Cárdenas, 2001).

Frente a este panorama, los jesuitas se valieron de la Misión Circular para evangelizar (Figura $\mathrm{N}^{\circ} 3$ ): consistía en un recorrido por los poblados del archipiélago, que se suspendía solo en invierno; los misioneros permanecían menos de una semana al año en estos poblados. Esta fórmula no habría resultado de no haber sido complementada con la acción del fiscal, una especie de diácono que sigue vigente hasta el día de hoy. Era un lugareño que atendía a la iglesia local, convocando a la población a rezar, en- señarle la doctrina y, además, bautizaba y ayudaba a bien morir. Según Cárdenas (2001), la inteligencia jesuita consiste en reemplazar el machi por este "chamán de la nueva religión", quien atendía la iglesia los 365 días del año.

Se adoptó la costumbre de visitar, todos los años, entre septiembre y mayo -y aun junio- cada una de las capillas del itinerario, por penoso y dilatado que fuera para los dos a tres curas que solían existir para la "misión general". Jamás dejaron de atender a los fieles que esperaban con ilusión a los visitantes.

Las capillas a las que asistían se construyeron junto a la playa. En ellas se reunían indígenas y españoles solo durante los días de la misión. Después, los lugareños volvían a habitar sus casas y retomaban sus quehaceres cotidianos.

Figura $\mathrm{N}^{\circ} 3$

Misión circular de los jesuitas en el archipiélago de Chiloé (1757-1758)
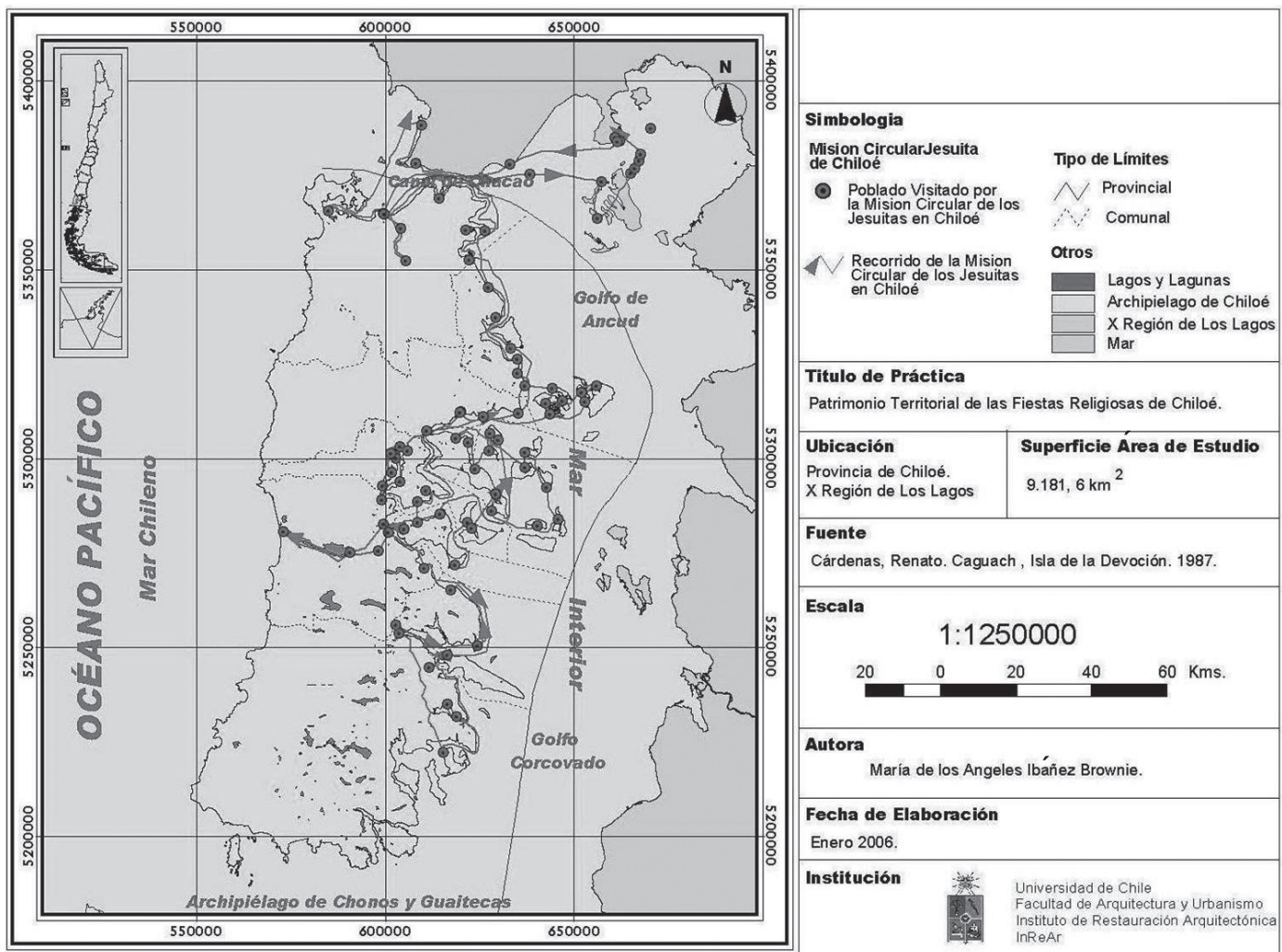

Fuente: INREAR, 2006. 
Para la construcción de las capillas se usaba el sistema indígena de trabajo Ilamado minga. Desde las capillas, los vecinos salían a recibir a los misioneros y los acompañaban en procesión hacia la iglesia.

Finalizada la estadía de los misioneros, las comunidades quedaban a cargo de la atención del fiscal, que se ocupaba de las extremaunciones, bautizos y sepultaciones.

Cada comunidad había llegado a ordenar su vida en función del día de la visita del patíru o día santo. En esa ocasión, fiscales y patrones exhibían sus progresos, tanto en la catequización de los niños como en la decoración de las capillas. La visita significaba, además, una cierta competencia entre capillas en lo relacionado con las expresiones cristianas, toda vez que era la oportunidad en que se celebraba el día del Santo Patrono.

Difícil era modificar el esquema y por eso se mantuvo la fórmula de visitar todos los pueblos, saliendo del hospicio de Castro a recorrer y adoctrinar a todas las capillas del archipiélago, hasta las más recónditas.

Los jesuitas empleaban regularmente tres días en cada capilla, excepto en Carelmapu, que demandaba hasta cuatro días: por ser población extrema, no podía ser visitada durante el año, dada la dificultad de vadear el canal. La otra excepción era Caylín, cuyos habitantes neófitos necesitaban más tiempo para consolidar su fe. En ese caso, la misión llegaba a durar cinco días (Urbina, 1990).

En todas las capillas se cumplía el mismo trabajo: pláticas, misas, procesiones, bautizos, casamientos, confesiones, numeraciones. Los religiosos de la Misión Circular Ilevaban un padrón en el que registraban la totalidad de la población indígena de cada pueblo, lo que les permitía saber con certeza cuántos nacen y cuántos mueren de año en año.

Los jesuitas hacían una gran procesión cada cuatro o cinco capillas, a la que se solía llamar vuta-procesión o procesión penitencial.

Las primeras fiestas religiosas de Chiloé se remontan a los tiempos en que se inicia- ba la evangelización católica en la isla, bajo el lema de evangelizar la cultura. Adaptada a los parámetros culturales que ya existían, fue prontamente comprendida y asimilada por los aborígenes que dotaron al espacio utilizado de una carga mágica.

\section{La iglesia, centro espiritual de la comarca: el patrimonio tangible}

Ni los chonos ni los veliches poseían templos; tampoco centros de reunión social. Las actividades religioso-sociales, como los nguillatún, se realizaban cada año en un lugar diferente. Así se explica que a medida que los jesuitas iban, evangelizando los distintos poblados, iban, también, construyendo iglesias "... para que hubiese parte fija donde todos acudiesen a rezar/.../ porque de esta manera no sería necesario ir a buscar de rancho en rancho ni celebrar el santo sacrificio en el toldo que más decente era celebrar en casa, aunque pobre, consagrada y destinada a Dios" (Cárdenas, 2001: 13).

Dado el poco tiempo que se quedaban los jesuitas en los distintos poblados $-y$ como una manera de no irrumpir tan agresivamente en la población-, la construcción de las iglesias fue, en un inicio, similar a la de las viviendas veliches, esto es, de techo pajizo y paredes de tablazones: "...se componen de unos postes de madera, con otros palos que se les arriman formando las paredes y el techo cubierto de paja sobre algunas tijeras, sin que se gaste en toda su formación un clavo, porque todo es amarrado con unas raíces y yerbas que trepan por los árboles, y que Ilaman boqui..." (Cárdenas, 2001: 15).

Paulatinamente, se introdujo la arquitectura europea, pero adecuada al medio chilote, esto es, construida con el material que abundaba en la isla: la madera.

La iglesia se transformaba, así, en el centro reconocible de cada sector o isla, el lugar de convocatoria periódica y el área sagrada. Es la forma más efectiva de congregación nativa que se pudo lograr, ante la imposibilidad de establecer pueblos de indios, como era la intención de la Coro- 
na. Además, se procuró que la construcción fuera hecha cercana a la playa o muelle, “...para que los distantes no tuviesen que caminar tanto, y las dichas capillas se pusieran junto a las playas, para que llegando allí los padres con sus piraguas, sin mucha fatiga puedan empezar luego los ministerios, junta ya la gente". (Cárdenas, 2001: 16).

Como una forma de hacerse presente, la Misión Circular dio forma a un calendario, con rituales muy dogmáticos, para establecer sus acciones religiosas, que se reiteraron por siglos y que fueron sostenidos localmente por el fiscal.

Anexa a estas iglesias se levantó una casa menor llamada casemita (casa de mita) que servía de albergue para los sacerdotes. Con el tiempo se incorporaron, también, los cementerios próximos a estas construcciones, evitando que los enterramientos se hicieran a la usanza india (Cárdenas, 2001).

La idea del templo como centro del espacio chilote se ha mantenido hasta estos días. Desde la perspectiva arquitectónica, esta idea se ha reiterado en las sucesivas investigaciones que tratan el tema. Todas coinciden en la importancia que adquiere la localización del templo y de qué manera los elementos componentes de espacio chilote -la explanada que permite la reunión de la comunidad, el cementerio adyacente al templo y un lugar optativo para el muelle o puerto- responden compositivamente según sea la dimensión del poblado y su grado de urbanización. El análisis de diversos casos ha permitido afirmar que el espacio religioso chilote tiene como centro ordenador a la iglesia. Precisamente a partir de ella los elementos complementarios juegan un rol que depende de la magnitud y grado de desarrollo de cada poblado.

\section{Las fiestas religiosas chilotas: el patrimonio intangible}

Las fiestas religiosas de Chiloé, que surgen como manifestación pública de su cultura, expresan el poder de la devoción y las creencias, férreamente arraigadas en el pueblo. Como ninguna otra actividad, estas celebraciones propician el encuentro social.
Durante el año se celebran, en total, 362 festividades religiosas en la provincia de Chiloé. Sus características varían según la cantidad de atributos, la devoción que posee y la fecha en que tiene lugar.

Respecto de la distribución anual se puede concluir que la mayoría de las festividades se concentran entre diciembre y febrero. Esta evidencia no permite colegir que exista directa relación con el clima, ya que bajo esta lógica enero debiera ser el mes con más celebraciones. Asimismo, en los meses de invierno -junio, julio y agosto- no se celebrarían 100 fiestas religiosas. Tampoco se explicaría el que en primavera exista menor cantidad de celebraciones que en invierno. La Figura $N^{\circ} 4$ muestra, por lo demás, que el periodo otoñal -abril y mayo- es el que menos cantidad de celebraciones concentra. La irregular distribución anual de las celebraciones religiosas se explica porque la mayor parte de los habitantes desempeña labores agrícolas. De allí que los valores mínimos de la Figura $\mathrm{N}^{\circ} 4$ estén dados por los tiempos de siembra (período marzo, abril y mayo) y de cosecha (septiembre, noviembre y enero); los máximos, por su parte, corresponden a los meses posteriores a esas actividades agrícolas.

La mayoría de las fiestas celebra a la Virgen (Figura $\mathrm{N}^{\circ} 5$ ), cualquiera sea su advocación (52 festividades, lo que equivale al $57 \%$ de la provincia); en segundo término, se festeja a los santos (28 festividades, esto es, el $25 \%$ provincial). Las fiestas cuyo centro de celebración es Cristo, se cuentan en tercer lugar (13 romerías, es decir, el 16\% provincial).

En relación con la santería patronal chilota cabe indicar que la Virgen de Lourdes es la más popular, seguida por la Virgen del Carmen y la imagen de los Nazarenos. Entre los santos, los que suman más devotos son: San Miguel, San Francisco de Asís, San Antonio de Padua, San Pedro, San José, San Judas Tadeo y San Juan. Sin embargo, la fiesta de mayor importancia en la isla, por la cantidad de gente congregada, es la del Cristo de Caguach.

En cuanto a los lugares en que se realizan las fiestas religiosas que poseen proce- 
Figura $\mathrm{N}^{\circ} 4$

Distribución anual de las celebraciones religiosas, provincia de Chiloé

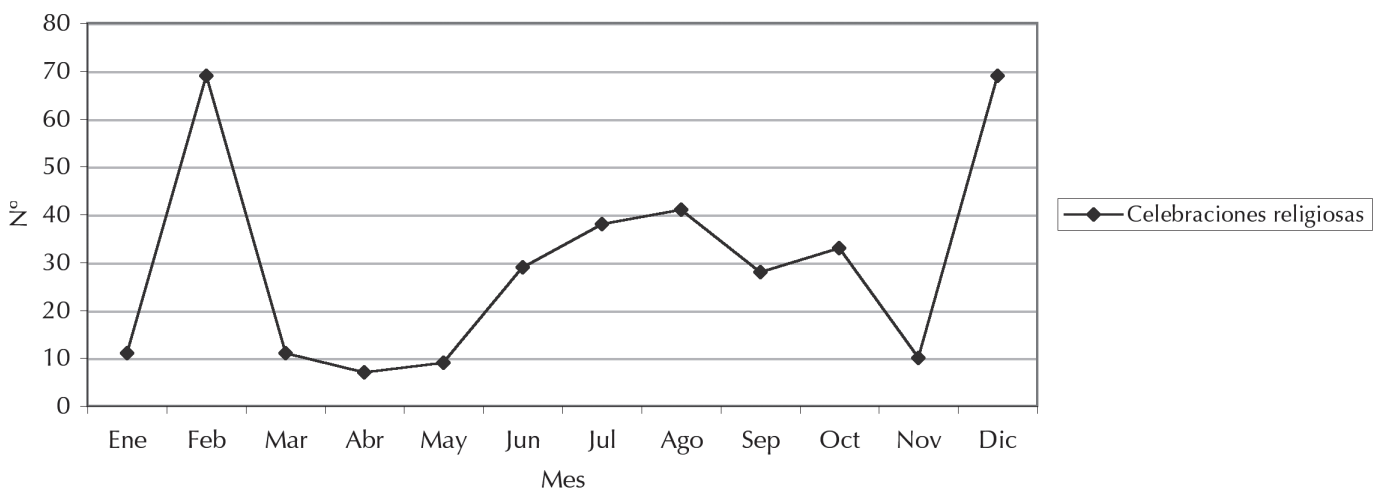

Fuente: INREAR, 2006

sión en la provincia de Chiloé, se ha realizado un análisis de acuerdo al tipo de imagen (Cristos o Nazarenos, Vírgenes y Santos).

Aquellas cuya imagen de devoción es un Cristo o Nazareno (Figura $\mathrm{N}^{\circ}$ 6) tienen un patrón disperso, que se da en las localidades del mar interior, tanto en la costa oriental de la isla Grande como en algunas islas del microarchipiélago de Quinchao. Tal es el caso del Jesús Nazareno de Caguach, tal vez la fiesta más importante de Chiloé. Sin embargo, se observan, con alguna nitidez, dos áreas pequeñas: una, entre la localidad de Choen (Quemchi), por el norte, hasta la localidad de Aituy (Queilen), por el sur; aquí es donde está la mayor cantidad de devotos de la imagen de Cristo. La otra área corresponde a la que va desde la localidad de Carahue hasta las islas de Coldita y Laitec, en la comuna de Quellón.

En los casos en que la imagen de veneración es la Virgen (Figura $N^{\circ} 7$ ), al igual que en el caso de los Cristos, la concentración se da en la costa oriental de la isla Grande; asimismo, en algunas islas del microarchipiélago de Quinchao y las islas de Quehui, Tranqui, Coldita y Laitec. El área de influencia se extiende entre la localidad de Queler (Quemchi) por el norte hasta las localidades de las islas de Coldita y Laitec (Quellón), por el sur.
Figura $N^{\circ} 5$

Porcentaje por tipo de imagen de devoción, provincia de Chiloé

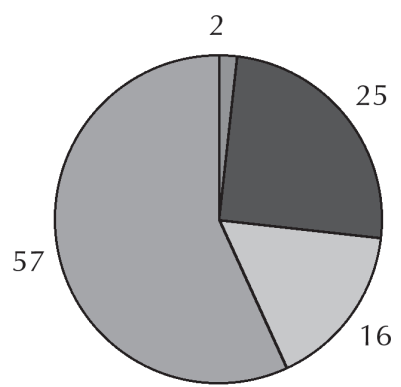

口Ánimas

口antos

C Cristos

$\square$ Virgen

Fuente: INREAR, 2006.

Las festividades marianas tienden a concentrarse en los poblados adyacentes al canal Caucahue, como así también en los caseríos vecinos a la conjunción de los canales Dalcahue y Quinchao con el paso Tenaún; de igual forma, se puede apreciar una concentración en las localidades que bordean al estero Castro. La mayor cantidad de fiestas marianas se encontraría en el poblado de Meulin, con cuatro festividades, en la isla de igual nombre (Quinchao). Tres romerías se dan en la localidad de Ahoni y tres en Lelbun (Queilen). Y dos romerías a la Virgen tienen lugar en las siguientes locali- 
dades: Los Ángeles (Castro), Tey (Castro), Apiao (Quinchao) y Coldita (Quellón).

Las fiestas religiosas dedicadas a los santos (Figura $N^{\circ} 8$ ), por su parte, tienden a emplazarse en las localidades costeras del borde oriental de la isla Grande de Chiloé, algunas islas del microarchipiélago de Quinchao y las islas de Quehui (Castro), Cailin y Laitec (Quellón). El área de influencia va desde el poblado de Colo (Quemchi) por el norte hasta las islas de Cailin y Laitec (QueIlón). En este caso, Ilama poderosamente la atención que en algunas localidades el topónimo lleva el nombre del Santo Patrón del lugar, como San Juan en Dalcahue o San Antonio en Quellón.

En síntesis, la mayor parte de las celebraciones religiosas en Chiloé se realizan en el borde oriental de la isla Grande de Chiloé, algunas islas del microarchipiélago de Quinchao y las islas de Quehui y Chelin en la comuna de Castro, la isla de Tranqui en la comuna de Queilen y las islas Coldita, Cailin y Laitec en la comuna de Quellón. Se puede afirmar que el Chiloé religioso tiene como límite, por el norte, la localidad de Queler (Quemchi), próxima al canal Caucahue, y por el sur, la bahía Quellón, incluyendo las islas Coldita, Cailin y Laitec.

Se comprueba que los lugares donde se han mantenido las fiestas religiosas con procesión de imagen (Figura $N^{\circ}$ 9) corresponden fundamentalmente a sectores rurales (caseríos o villorrios y caletas de pescadores artesanales). Cabe destacar, además, que las localidades que poseen la mayor cantidad de fiestas religiosas durante el año tienen una difícil accesibilidad (o son islas alejadas del mar interior o sus vías de acceso terres-

Figura $\mathrm{N}^{\circ} 6$

Carta de las fiestas de imágenes de cristos y sus procesiones religiosas de la provincia de Chiloé

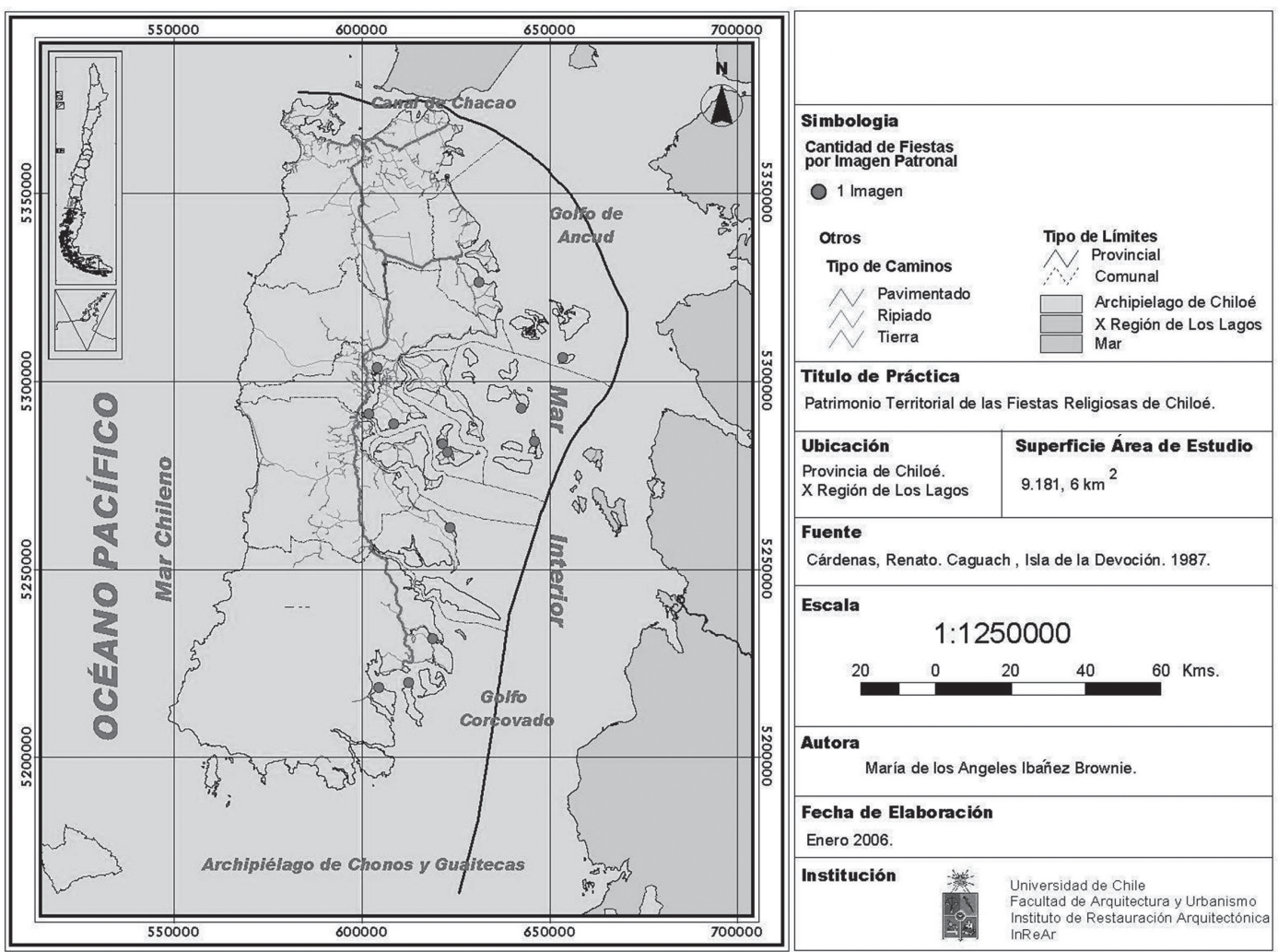

Fuente: INREAR, 2006. 
tre son apenas una huella en el paisaje). Meulin, por ejemplo, concentra cinco fiestas religiosas durante el año: localizada en la isla del mismo nombre, en el microarchipiélago de Quinchao, solo se conecta con el pueblo de Achao a través de lanchas.

\section{La hegemonía del templo chilote}

Entre los años 2005 y 2006 el Instituto de Restauración Arquitectónica de la Facultad de Arquitectura y Urbanismo de la Universidad de Chile (InReAr) realizó una investigación cuyo propósito central era demostrar que el templo aún tenía la condición de centro del territorio chilote (herencia del ordenamiento territorial jesuita). Se concluyó que, efectivamente, a pesar de la fuerza con que ha irrumpido la globaliza- ción de la cultura en todas sus expresiones, el templo no ha perdido su hegemonía. El análisis derivado de las observaciones en terreno -particularmente para las fiestas patronales de cada poblado- y la bibliografía complementaria avalaron rotundamente la hipótesis formulada por los investigadores.

Conscientes del valor de la cultura chilota, de las singulares condiciones del territorio y de la peculiaridad de su modo de vida, la investigación hace foco en las festividades religiosas, en los templos, y particularmente en el espacio físico que comprometen las celebraciones.

Tanto los espacios religiosos como las fiestas patronales de Chiloé pueden ser considerados como remanentes del patrimonio histórico de la influencia de la Misión Circular jesuita sobre los pueblos indígenas evan-

Figura $\mathrm{N}^{\circ} 7$

Carta de las fiestas de imágenes de vírgenes y sus procesiones religiosas de la provincia de Chiloé
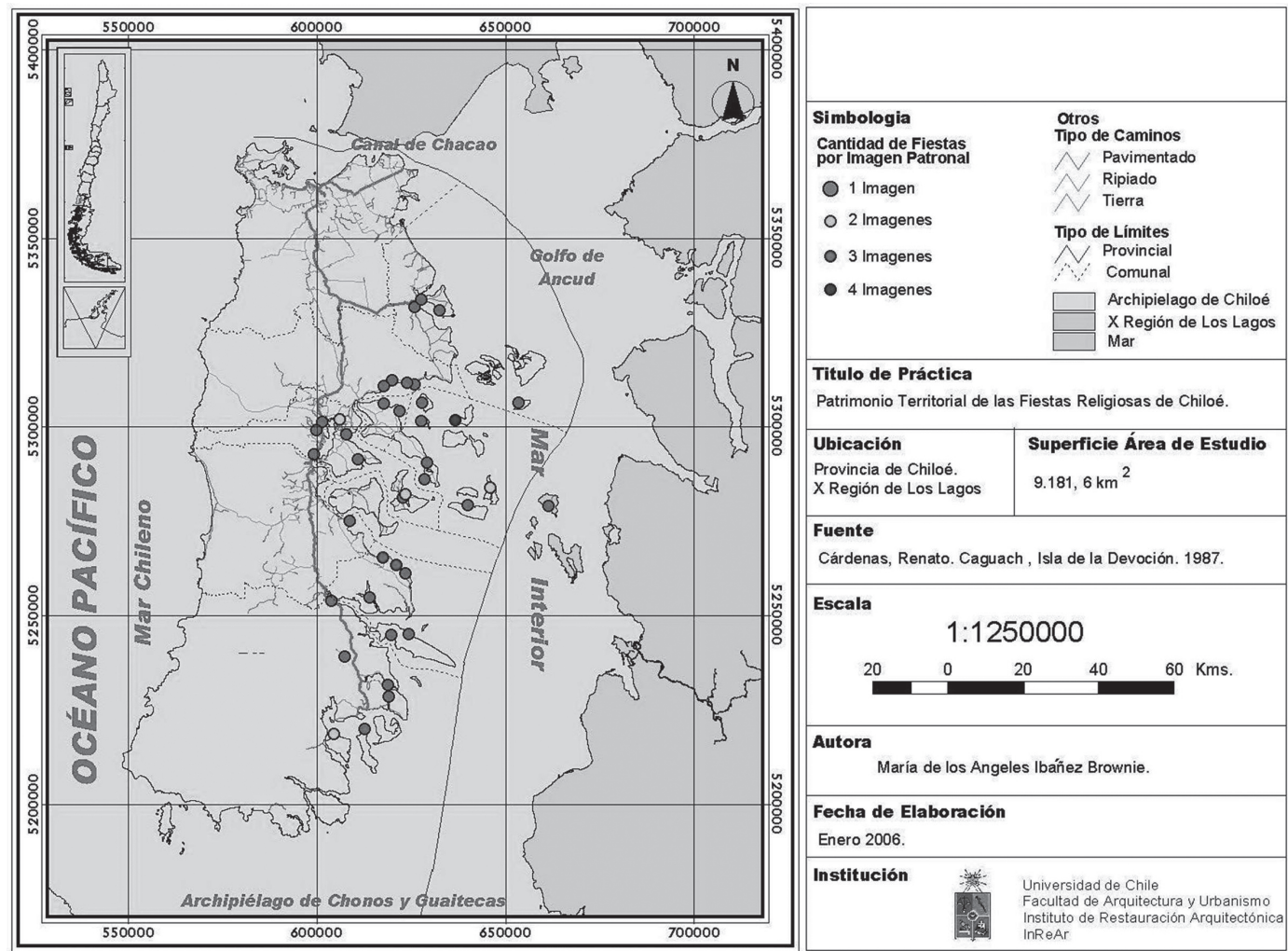

Fuente: INREAR, 2006. 
gelizados. Se expresan en la excepcionalidad de sus templos, en su santería, en la estructura de las fiestas y en la organización comunal, tan presente en el pueblo chilote.

Es claro que las festividades religiosas de Chiloé se relacionan, de preferencia, con un medio básicamente rural, donde el modo de vida se desarrolla bajo una economía campesina de autoconsumo en el cual priman las actividades agropecuarias de carácter extensivo, la pesca artesanal y la recolección marina. Desde un punto de vista social, se conservan los fuertes lazos de la familia como núcleo secular fundamental. El territorio abarcado comprende el sector norte $y$ oriente de la provincia, incluyendo tanto la isla Grande (con un eje de penetración hacia el poniente, en el centro de ella), así como las islas adyacentes situadas en el mar interior.
Se observa, asimismo, una dinámica espacial en torno a las fiestas religiosas, lo que involucra la pérdida de las áreas exteriores de la iglesia, según su jerarquía urbana: espacios que se destinan al culto y a la celebración son desplazados por la urbanización, a medida que la ciudad aumenta en tamaño y jerarquía. Si se considera que, además, el crecimiento de la planta urbana, por lo general, conlleva al surgimiento de nuevas iglesias para dar mayor y mejor servicio a la población, necesariamente la iglesia original pierde su calidad de centro geográfico y social, todo lo cual implica que en las ciudades el fenómeno de las fiestas religiosas sea bastante menor en cuanto a escala e implicancia.

Tal como lo reflejan los datos desprendidos de los casos de estudio (Cuadros $\mathrm{N}^{0} 1 \mathrm{y}$ $N^{\circ} 2$ ), el grado de importancia de la fiesta patronal, en el nivel local, así como también

Figura $\mathrm{N}^{\circ} 8$

Carta de las fiestas de imágenes de santos y sus procesiones religiosas de la provincia de Chiloé

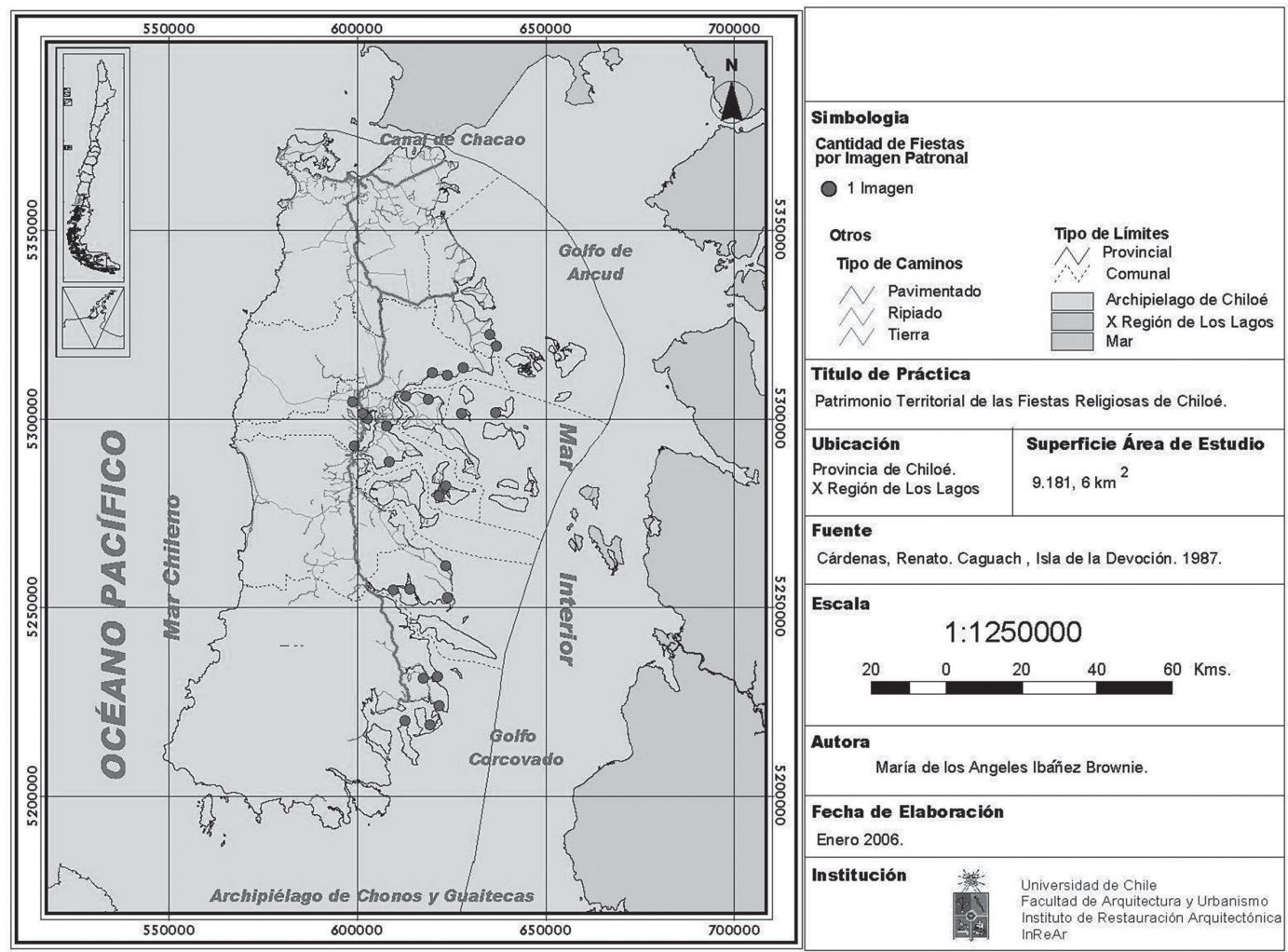

Fuente: INREAR, 2006. 
la mantención de la explanada jesuítica en condiciones naturales, está en relación directa con la superficie total del espacio religioso de cada localidad.

Respecto de las superficies religiosas analizadas, los valores más altos aparecen en las localidades de Castro y Caguach. Sin embargo, cabe señalar que en el caso de Castro el valor obtenido corresponde al perímetro y no a la superficie, ya que solo se utilizan las calles aledañas a la plaza y la iglesia, puesto que el área al interior de esta se encuentra urbanizada $y$, por tanto, no se usa (Figura $\mathrm{N}^{\circ} 10$ ).

En cambio, en el caso de Caguach se usa toda la superficie de la explanada (Figura $\mathrm{N}^{\circ}$ 11) y no solo sus vértices, tal como se hacía desde el inicio de la celebración en el siglo XVIII. Este hecho permitió que la iglesia de Caguach fuera elevada a la jerarquía de san- tuario, lo que implica la preservación de su explanada. Esta se constituye en una de las más extensas del archipiélago, ya que permite acoger la gran cantidad de fieles y peregrinos que se presentan el día de su fiesta.

En el caso de Llaullao existen dos elementos que han condicionado el tamaño de su espacio religioso. Por un lado, la inexistencia de un muelle, dado que la visión y crecimiento siempre se ha desarrollado hacia el interior de la isla Grande en vez de hacia el mar y, por otro, las características propias de la topografía local dominada por grandes lomajes, implican que el tamaño de su explanada sea reducido.

En relación con la superficie del territorio religioso respecto del tamaño de la planta de la entidad poblada, se observa que el porcentaje tiende a disminuir a medida que aumenta la categoría de "entidad urbana".

Figura $\mathrm{N}^{\circ} 9$

Carta de las fiestas patronales y sus procesiones religiosas de la provincia de Chiloé
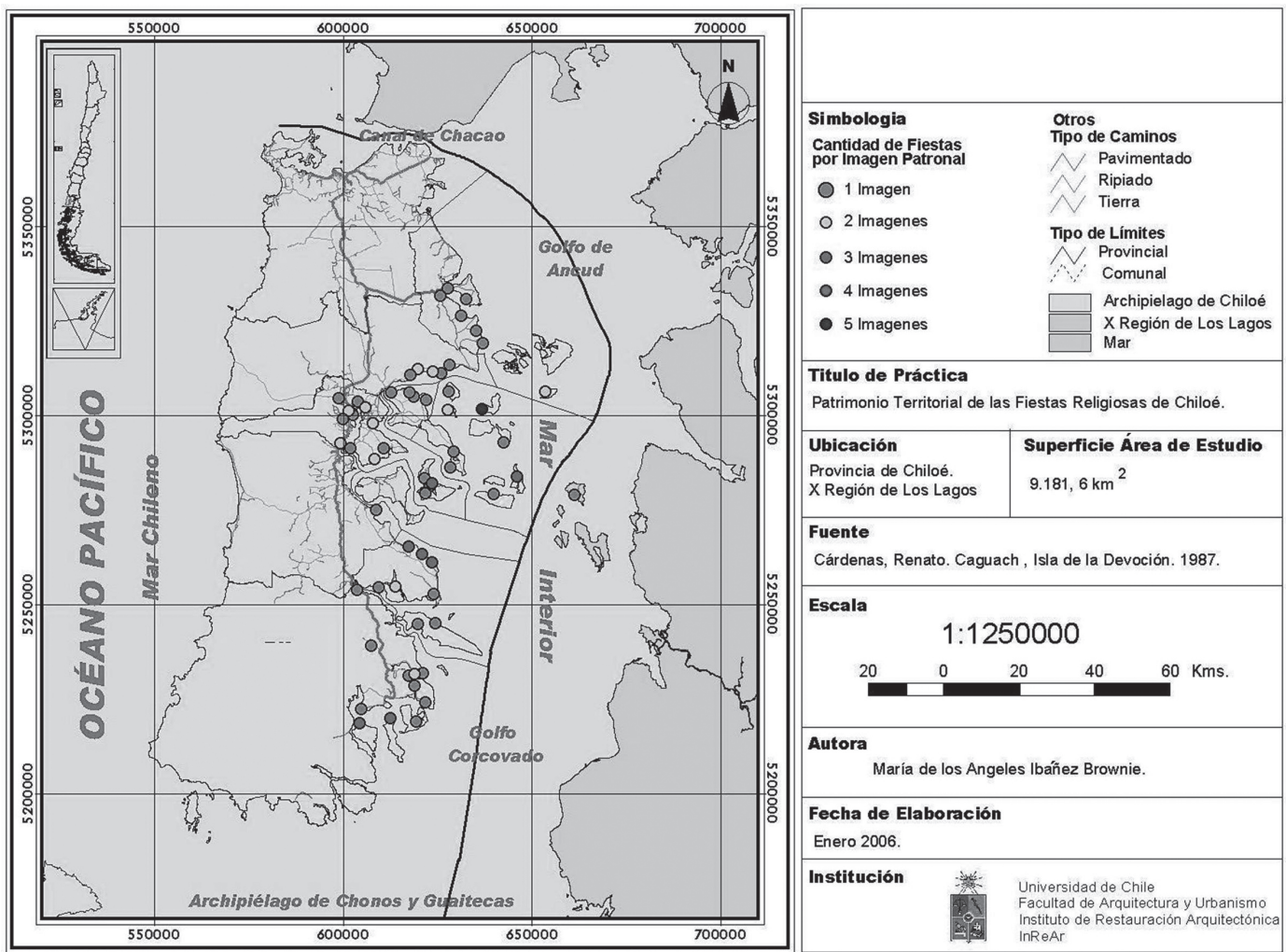

Fuente: INREAR, 2006. 
Cuadro $\mathrm{N}^{\circ} 1$

Medidas de los elementos que componen el espacio religioso por casos de estudio

\begin{tabular}{|c|c|c|c|c|c|c|c|c|}
\hline $\begin{array}{l}\overline{\tilde{\sigma}} \\
\stackrel{\infty}{\Xi}\end{array}$ & $\begin{array}{l}\text { స̃ } \\
\underline{0} \\
\frac{0}{\bar{U}} \\
\frac{\Sigma}{\Sigma}\end{array}$ & 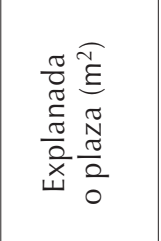 & 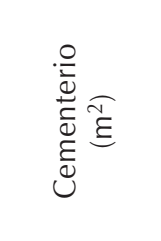 & $\begin{array}{l}\widetilde{\mathcal{I}} \\
\text { है } \\
\frac{\widetilde{\sigma}}{\tilde{U}} \\
\frac{\mathbb{U}}{00}\end{array}$ & 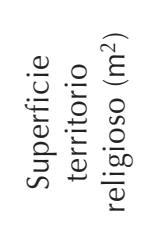 & 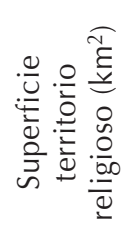 & 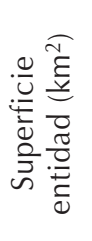 & 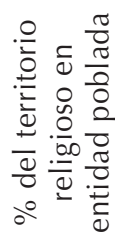 \\
\hline Caguach & 352,84 & $30.456,93$ & $3.590,47$ & $1.126,26$ & $35.526,5$ & 0,04 & 1,38 & 2,57 \\
\hline Llaullao & 0,00 & $2.467,98$ & $3.816,29$ & 341,00 & $6.625,27$ & 0,01 & 0,45 & 1,47 \\
\hline Achao & $1.806,53$ & $4.610,41$ & $11.388,65$ & 576,00 & $18.381,59$ & 0,02 & 1,84 & 1,00 \\
\hline Castro & $1.204,35$ & $22.525,15$ & $35.541,56$ & $1.691,74$ & $60.962,79$ & 0,06 & 7,38 & 0,83 \\
\hline
\end{tabular}

Fuente: INREAR, 2006.

Cuadro $\mathrm{N}^{\circ} 2$

Distancia lineal de cada elemento del espacio religioso a partir del templo. Según caso de estudio

\begin{tabular}{|l|c|c|c|c|}
\hline \multicolumn{1}{|c|}{ Lugar } & Distancia desde & Muelle $(\mathrm{m})$ & Explanada o plaza $(\mathrm{m})$ & Cementerio $(\mathrm{m})$ \\
\hline Caguach & Iglesia & 0 & 0 & 0 \\
Llaullao & Iglesia & N/E $(315)$ & 0 & 0 \\
Achao & Iglesia & 295 & 10,45 & 340 \\
Castro & Iglesia & 305 & 30 & 570 \\
\hline
\end{tabular}

Fuente: INREAR, 2006.

Finalmente, se consideró la variable distancia, en el entendido que el modelo concéntrico del espacio religioso de Chiloé deriva hacia un modelo disperso conforme el carácter del poblado se va aproximando físicamente al concepto de ciudad.

Así se explica que en una primera instancia el villorrio de Caguach se aproxima al patrón concéntrico, en el que la iglesia constituye el elemento nuclear. Se comprende, también, que entre la aldea de Llaullao, el pueblo de Achao y la ciudad de Castro, el modelo se haga cada vez más disperso (o multinuclear). Coincide con que, en el último caso, la iglesia no es propietaria única de los bienes: parte del dominio está en manos de instituciones laicas.

\section{Consideraciones finales}

El rol de la iglesia, como ente ordenador del espacio chilote, no tiene el mismo efecto territorial, puesto que su trascendencia está condicionada a la categoría de entidad poblada en que se emplaza su espacio religioso. Esto se traduce en una relación inversa, es decir, a mayor categoría de una entidad poblada chilota, menor será el papel que juega el templo como punto de partida de la armonía territorial instaurada por los jesuitas.

El espacio religioso chilote ha materializado de algún modo la condición de cobijo o abrigo que se precisa en latitudes de clima tan severo. Aun así, ajenos a los rigores de 
Figura $\mathrm{N}^{\circ} 10$

Uso de procesión religiosa patrimonial por cada caso de estudio
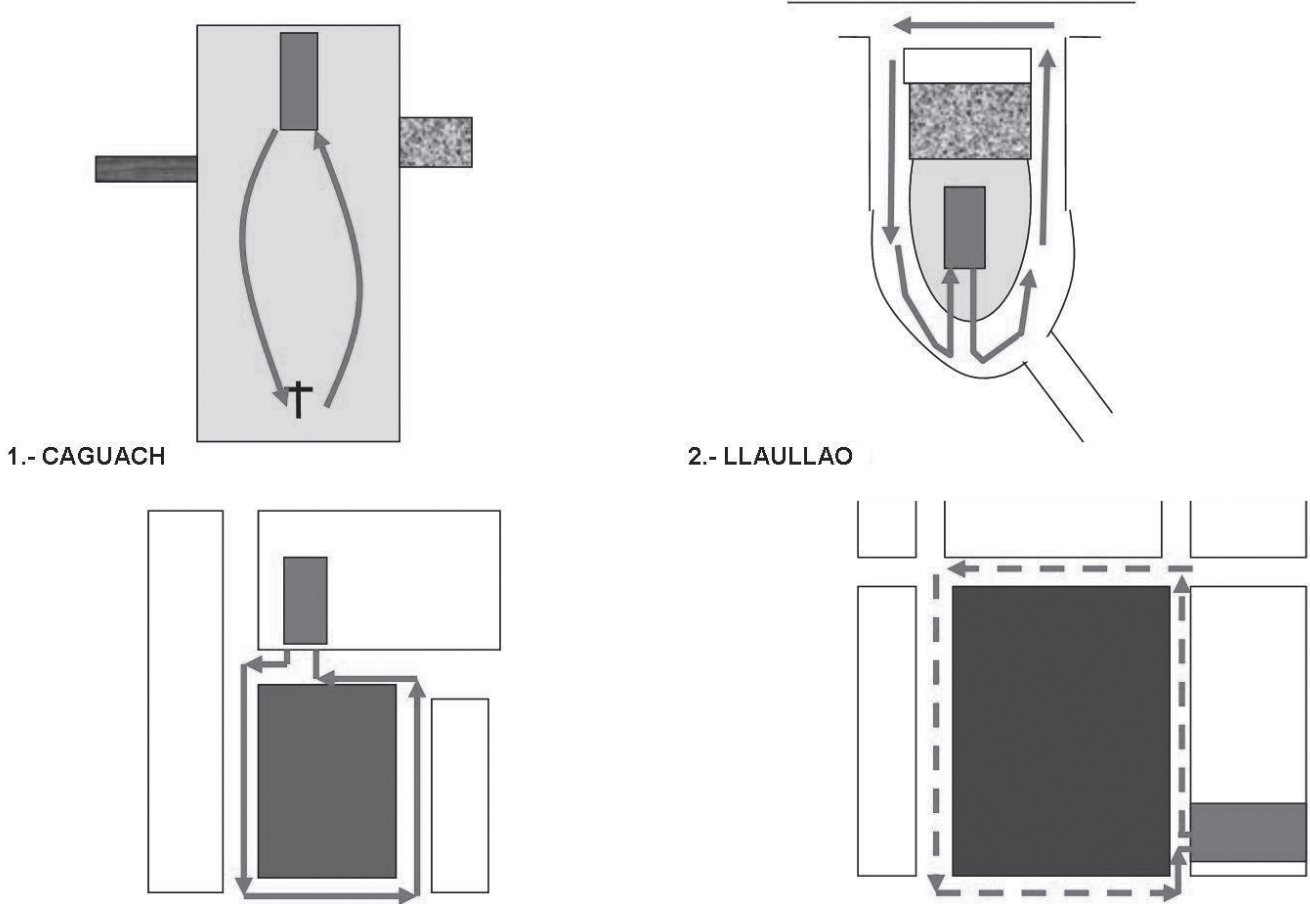

3.- $\mathrm{ACHAO}$
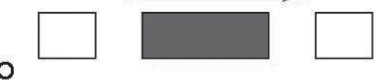

4- CASTRO

Fuente: INREAR, 2006.

Figura $N^{\circ} 11$

Modelo evolutivo del espacio religioso chilote

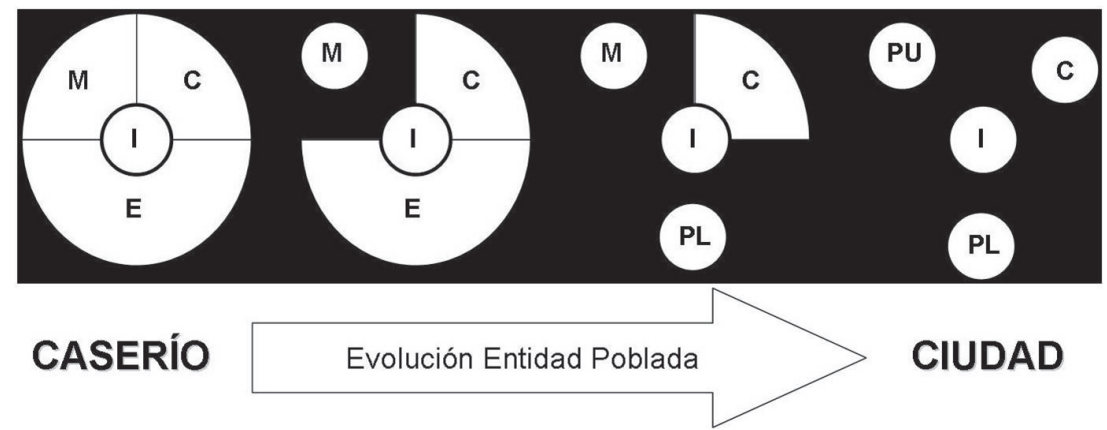

Leyenda: iglesia (i), cementerio (c), explanada jesuítica (e), muelle (m) y plaza cívica (pl). Fuente: Gallardo et al., 2006. 
la naturaleza, los habitantes construyen ese virtual lugar de encuentro, fieles a la tradición y a su muy singular manera de concebir la vida comunitaria.

La plurivalencia de estos lugares de encuentro religioso tiene un poderoso contenido mentifacto. Vale decir, son mucho más que una visión geométrica o física del espacio, en el cual confluyen simultáneamente el valor histórico, el social, el económico y el cultural.

Hasta cierto punto, el espacio religioso chilote se ha logrado adaptar a los cambios arrastrados por la globalización. Sin traicionar la idea central -el ser un foco de reunión para las comunidades de Chiloé-, ha puesto al servicio su estructura.

Los espacios religiosos chilotes han sido paulatinamente reconocidos por su gravitación en los encuentros multitudinarios que surgen durante las festividades consagradas al patrono o a la virgen de la localidad. Ya es tiempo de que se consideren de manera oficial en los programas culturales, y particularmente en la elaboración de las políticas de planificación territorial. Sería la mejor manera de garantizar su permanencia en el tiempo, poniendo a salvo una buena parte de la identidad de la cultura chilota.

\section{Referencias bibliográficas}

BERG, L. Conservación de las iglesias de Chiloé. Revista Arquitectura, 1998, No 3, p. 3-39.

BERGER, P. La désécularisation du monde: un point de vue global. En: BERGER, P.; WEIGEL, G. \& MARTIN, D. et al. Le réenchantement du monde. Paris: Bayard Éditions, 2001.

BERTRAND, J. P. Geografía y peregrinaciones. En: GRUPO DE ESTUDIO APROXIMACIÓN CULTURAL EN GEOGRAFÍA, UNIÓN GEOGRÁFICA INTERNACIONAL. Coloquio internacional Geografía de las Religiones. Ciudad de México: Grupo de Estudio Aproximación Cultural en Geografía, Unión Geográfica Internacional, 1999, p. 220-232.
BLANCARTE, R. Historia de la Iglesia Católica en México. Ciudad de México: Fondo de Cultura Económica / El Colegio Mexiquense, 1992.

BRAVO, M. La cultura chilota y su expresión territorial en el contexto de la globalización de la economía. Tesis título profesional de Geógrafo. Santiago: Escuela de Geografía, Facultad de Arquitectura y Urbanismo, Universidad de Chile, Chile, 2004.

CAPACCI, A. Los santuarios en Italia: encuentro entre religión y turismo. En: GRUPO DE ESTUDIO APROXIMACIÓN CULTURAL EN GEOGRAFÍA, UNIÓN GEOGRÁFICA INTERNACIONAL. Coloquio internacional Geografía de las Religiones. Ciudad de México: Grupo de Estudio Aproximación Cultural en Geografía, Unión Geográfica Internacional, 1999, p. 257-270.

CÁRDENAS, R. Los pilares de la evangelización en Chiloé. Castro: Archivo Bibliográfico y Documental de Chiloé. Documento no publicado, 2001.

CÁRDENAS, R. y TRUJILLO, C. Caguach, isla de la devoción. Religiosidad popular de Chiloé. Santiago: Ediciones Literatura Americana Reunida, 1987.

CASILLAS, R. La pluralidad religiosa en México. En: GIMÉNEZ, G. (Coord.). Identidades religiosas y sociales en México. Ciudad de México: IFAL, Instituto de Investigaciones Sociales, UNAM, 1966.

CLAVAL, P. La Geografía Cultural. Buenos Aires: Eudeba, 1995.

GALLARDO, F. et al. Arquitectura y fiestas religiosas: procesos de territorialización en Chiloé. Santiago: Instituto de Restauración Arquitectónica, Facultad de Arquitectura y Urbanismo, Universidad de Chile. Documento no publicado, 2006.

HARVEY, D. Teoría, leyes y modelos en Geografía. Madrid: Ed. Alianza, 1983.

HAGGETT, P. Geografía, una síntesis moderna. Barcelona: Editorial Omega, 1988. 
INSTITUTO NACIONAL DE ESTADÍSTICAS (INE). Chile: ciudades, pueblos, aldeas y caseríos. Santiago: INE, 2005.

INSTITUTO DE RESTAURACIÓN ARQUITECTÓNICA (INREAR). Patrimonio territorial de las fiestas religiosas de Chiloé. Práctica profesional título de Geógrafo. Santiago: Escuela de Geografía, Facultad de Arquitectura y Urbanismo, Universidad de Chile, Chile, 2006.

MANGANO, S. Territorio y santuarios: el caso Liguria. Roma: documento no publicado, 1990

MODIANO, I. Precedentes teóricos y formales del tipo de iglesias de Chiloé. Revista CA, 1994, No 78, p. 42-44.

MONTECINOS, H. Las iglesias misionales de Chiloé. Santiago: Universidad de Chile, Facultad de Arquitectura y Urbanismo, 1995.

PARKER GUMUCIO, C. The sociology of religion in Latin America. Teaching and Re- search. Social Compass, 1994, vol. 3, No 41, p. 339-364.

ROSENDAHL, Z. Spaço \& religión. Una abordagem geográfica. Rio de Janeiro: Universidad de Río de Janeiro, 1996.

ROSENDAHL, Z. Paisagem, tempo e cultura. Rio de Janeiro: Universidad de Río de Janeiro, documento no publicado, 1998.

ROSENDAHL, Z. Hieropolis: o sagrado e o urbano. Rio de Janeiro: Universidad de Río de Janeiro, documento no publicado, 1999 .

URBINA BURGOS, R. Las misiones franciscanas de Chiloé a fines del siglo XVIII: 1771-1800. Valparaíso: Editorial Elártole, 1990.

VÁSQUEZ DE ACUÑA, I. Costumbres religiosas de Chiloé y su raigambre hispana. Santiago: Ediciones Universitarias, 1956.

VUKONIC, B. Tourism and religion. New York: Editorial Pergamon, 1996. 